\title{
Protective Effects of Cyclo(L-Leu-L-Tyr) against Postischemic Myocardial Dysfunction in Guinea-Pig Hearts
}

\author{
Kumiko Mitsui-Saitoh,${ }^{a}$ Tadashi Furukawa, ${ }^{b}$ Takashi Akutagawa, ${ }^{b}$ Keiko Hasada, ${ }^{a, e}$ \\ Hideki Mizutani ${ }^{a}$ Yumi Sugimoto, ${ }^{d}$ Jun Yamada, ${ }^{d}$ Masatake Niwa, ${ }^{b}$ Yoshihiro Hotta,${ }^{a, c}$ and \\ Yoshiaki TAKAYA ${ }^{*}, b$ \\ ${ }^{a}$ College of Pharmacy, Kinjo Gakuin University; Omori, Moriyama, Nagoya 463-8521, Japan: ${ }^{b}$ Faculty of Pharmacy \\ Meijo University; Yagotoyama, Tempaku, Nagoya 468-8503, Japan: ${ }^{c}$ Department of Pharmacology, Aichi Medical \\ University School of Medicine; Nagakute, Aichi 480-1195, Japan: ${ }^{d}$ Laboratory of Pharmacology, Department of Clinical \\ Pharmacy, Yokohama College of Pharmacy; Totsuka, Yokohama 245-0066, Japan: and e Graduate School of \\ Pharmaceutical Sciences, Nagoya City University; Tanabe-dori, Mizuho, Nagoya 467-8603, Japan.
}

Received June 23, 2010; accepted December 27, 2010; published online January 6, 2011

The protective effects of cyclic dipeptides in alcoholic beverages were investigated in the perfused guinea-pig hearts subjected to ischemia and reperfusion. Subsequently, in order to determine the importance of cyclic dipeptide structure, the effects of cyclo(L-Leu-L-Tyr) (CLY) were compared with those of the newly synthesized non-cyclic dipeptides, L-Leu-L-Tyr (LY) and L-Tyr-L-Leu (YL). After reperfusion, pressure recovery (\%) in the left ventricle reached a peak of over $90 \%$ in the presence of $\mathrm{CLY}\left(10^{-6} \mathrm{M}\right.$ and $\left.10^{-5} \mathrm{M}\right)$ (control: $\left.22.9 \%\right)$. The recovery by LY and YL was significantly lower than that by cLY, and ATP levels simultaneously monitored using ${ }^{31} \mathrm{P}$ NMR were already lower during the ischemic end period than those observed with cLY treatment. In perfused mitochondrial preparations, cLY significantly inhibited mitochondrial $\mathrm{Ca}^{2+}\left(\left[\mathrm{Ca}^{2+}\right]_{\mathrm{m}}\right)$ elevation in a similar way to that of the mitochondrial permeability transition pore (MPTP) inhibitor cyclosporin A. In vitro electron paramagnetic resonance (EPR) revealed that the active oxygen radicals quenching activity of cLY was greater than those of non-cyclic dipeptides. cLY inhibited caspase-3-induced apoptosis. The cyclic dipeptide structure inhibits opening of the MPTP by preventing $\left[\mathrm{Ca}^{2+}\right]_{\mathrm{m}}$ overload-induced apoptosis related to mitochondrial active oxygen radical accumulation in ischemia-reperfusion hearts.

Key words cyclic dipeptide; ischemia-reperfusion injury; ${ }^{31} \mathrm{P}-\mathrm{NMR}$; electron paramagnetic resonance; mitochondrial permeability transition pore; apoptosis

Cyclic dipeptides have been detected in a variety of natural products as well as in processed foods, beverages, and food and beverage ingredients. A number of bitter prolinebased cyclic dipeptides, namely cyclo(Ala-Pro), cyclo(IlePro), cyclo(Leu-Pro), cyclo(Met-Pro), cyclo(Phe-Pro), and cyclo(Pro-Pro), have now been identified in beer ${ }^{1)}$ or aged sake. ${ }^{2)}$ Cyclic dipeptides, which are composed of other amino acids than proline, have been identified in the distilled residue of millet brandy (awamori), and many other cyclic dipeptide have been newly synthesized in studies on structure-activity interactions. ${ }^{3)}$ The ability of natural and synthesized cyclic dipeptides to scavenge active oxygen radicals has been measured by electron paramagnetic resonance (EPR), and the cardioprotective effects of these compounds have been investigated in perfused guinea-pig hearts subjected to ischemia and reperfusion. Pretreatment with cyclo(L-Leu-L-Tyr) (cLY) promoted optimal recovery after injury.

In order to determine the importance of the cyclic dipeptide in cardioprotection, the effects of cLY in guinea-pig hearts were compared with those of the newly synthesized non-cyclic dipeptides L-Leu-L-Tyr (LY) and L-Tyr-L-Leu (YL) (Fig. 1). We studied the effects of cLY, LY, and YL on sequential changes in left ventricular contractility as well as the cellular metabolism of high-energy phosphorous in isolated guinea-pig Langendorff hearts subjected to normothermic global ischemia and subsequent reperfusion. Additionally, mitochondrial $\mathrm{Ca}^{2+}\left(\left[\mathrm{Ca}^{2+}\right]_{\mathrm{m}}\right)$ uptake following changes in the perfusate acidity or $\mathrm{Ca}^{2+}$ content similar to those occurring at the end of ischemia or reperfusion after global is- chemia in Langendorff hearts were investigated prior to the administration of cyclic dipeptide. The role of $\left[\mathrm{Ca}^{2+}\right]_{\mathrm{m}}$ mediated injury was determined by investigating the mitochondrial permeability transition pore (MPTP) using openers and inhibitors of the MPTP, ${ }^{4,5)}$

Our results suggest that cyclic dipeptides inhibit the opening of the MPTP by preventing $\left[\mathrm{Ca}^{2+}\right]_{\mathrm{m}}$ overload-induced apoptosis in ischemic-reperfusion hearts. ${ }^{\text {) }}$ There is now evi-<smiles>CC(C)CC1NC(=O)NC1Cc1ccc(O)cc1</smiles>

cyclo(L-Leu-L-Tyr) (cLY)<smiles>CC(C)C[C@H](NC(=O)[C@H](N)Cc1ccc(O)cc1)C(=O)O</smiles><smiles>CC(C)CC(N)C(=O)NC(=O)Cc1ccc(O)cc1</smiles>

Fig. 1. Structures of Cyclic Dipeptide, cLY, and Non-cyclic Dipeptides, LY and YL 
dence that apoptosis, or programmed cell death, is an important response of the myocardium to ischemia that precedes cell necrosis and appears to contribute to the overall sequelae of cardiac injury. ${ }^{7-9)}$ Therefore, we examined the protective activities of cyclic dipeptides and non-cyclic dipeptides with respect to their reduction of caspase-3 activity-induced apoptosis.

\section{MATERIALS AND METHODS}

Chemicals Fura-2 AM was obtained from Dojindo Laboratories (Kumamoto, Japan). Methylenediphosphonic acid and cremophore EL were purchased from Molecular Probes (Eugene, OR, U.S.A.). 5,5-Dimethyl-1-pyrroline-1-oxide (DMPO) was obtained from Labotec (Tokyo, Japan). Hypoxanthine, atractyloside potassium salt (Atr), cyclosporin A (CsA), diethylene triamine penta acetic acid (DETAPAC), and xanthine oxidase (XOD) were from Sigma (St. Louis, MO, U.S.A.). FK506 was generously provided by Fujisawa Pharmaceutical Co. (Osaka, Japan). The CPP32/caspase-3 fluorometric protease assay kit was purchased from MBL (Nagoya, Japan). All other chemicals were of reagent grade.

Preparation of Cyclo(L-Leu-L-Tyr) To a solution of Ltyrosine methyl ester hydrochloride in dichloromethane at $-15^{\circ} \mathrm{C}$ was added one equivalent triethylamine, $N$-tertbutoxycarbonyl (BOC)-L-leucine, and a solution of dicyclohexacarbodiimide (DCC) in dichloromethane at $0{ }^{\circ} \mathrm{C}$. The reaction mixture was stirred at $0^{\circ} \mathrm{C}$ for $1 \mathrm{~h}$. The reaction solution was stirred at room temperature for $3 \mathrm{~h}$. The dicyclohexylurea was filtered from the reaction mixture. Dichloromethane was added to reaction mixture, and the reaction mixture was washed with $5 \% \mathrm{NaHCO}_{3}$, water, $1 \mathrm{M} \mathrm{HCl}$, water, and saturated $\mathrm{NaCl}$ solution. The organic layer was dried over anhydrous $\mathrm{Na}_{2} \mathrm{SO}_{4}$, filtrated, and evaporated. The residue was purified by silica gel column chromatography to afford $N$-BOC-L-Leu-L-Tyr methyl ester.

$N$-BOC-L-Leu-L-Tyr methyl ester was treated with $4 \mathrm{M}$ $\mathrm{HCl}-1,4-d i o x a n e$ at room temperature for $30 \mathrm{~min}$. The reaction mixture was evaporated. The residue was dissolved in $0.1 \mathrm{M}$ acetic acid-2-butanol, and to this solution was added one equivalent $N$-methyl-morpholine. The reaction mixture was refluxed for $3 \mathrm{~h}$ under $\mathrm{N}_{2}$. The reaction mixture was concentrated until crystal of cyclic dipeptide appeared. The crystal was collected by filtration, and was washed with small amounts of 2-butanol followed by silica gel column chromatography.

Cyclo(L-Leu-L-Tyr) Colorless powder. $[\alpha]_{\mathrm{D}}:+222.3$ $\left(c=0.10\right.$, methanol). IR $v_{\max }(\mathrm{KBr}): 3312,3204,3084,2953$, $1676,1661 \mathrm{~cm}^{-1}$. ${ }^{1} \mathrm{H}-\mathrm{NMR}$ (DMSO- $\left.d_{6}, 400 \mathrm{MHz}\right) \delta_{\mathrm{H}}: 0.14$ (ddd, $J=5.0,9.2,13.8 \mathrm{~Hz}), 0.63(3 \mathrm{H}, \mathrm{d}, J=6.6 \mathrm{~Hz}), 0.65(3 \mathrm{H}$, d, $J=6.6 \mathrm{~Hz}), 0.76(\mathrm{ddd}, J=5.0,11.9,13.8 \mathrm{~Hz}), 1.42(\mathrm{~m})$, $2.68(\mathrm{dd}, J=4.6,13.3 \mathrm{~Hz}), 3.01(\mathrm{dd}, J=3.7,13.8 \mathrm{~Hz}), 3.45$ (brdd, $J=4.1,8.3 \mathrm{~Hz}$ ), 4.06 (brs), $6.63(2 \mathrm{H}, \mathrm{d}, J=8.3 \mathrm{~Hz}$ ), $6.89(2 \mathrm{H}, \mathrm{d}, J=8.3 \mathrm{~Hz}), 8.03$ (s), 8.04 (s), 9.20 (s). ${ }^{13} \mathrm{C}-\mathrm{NMR}$ (DMSO- $\left.d_{6}, 125 \mathrm{MHz}\right) \delta_{\mathrm{C}}: 21.3,22.8,23.0,37.8,43.7,52.3$, 55.7, 114.9, 125.9, 131.3, 156.4, 166.3, 167.5. High-resolution FAB-MS: $\mathrm{C}_{15} \mathrm{H}_{21} \mathrm{~N}_{2} \mathrm{O}_{3} \quad 277.1516\left[(\mathrm{M}+\mathrm{H})^{+}\right.$, Calcd 277.1552]. Positive FAB-MS $m / z: 277(\mathrm{M}+\mathrm{H})^{+}$.

Animals Throughout the experiments, all animals were handled in accordance with the guidelines for animal experimentation set by the Japanese Association for Laboratory
Animal Science.

Langendorff Guinea-Pig Hearts-Heart Preparation and Examination Procedures Hartley strain guinea pigs of either gender weighing 300-350 g were anesthetized with diethyl ether and heparinized (250 IU, intraperitoneally (i.p.)). The heart was rapidly excised and the aorta was cannulated as described previously. ${ }^{10-12)}$ The Langendorff heart preparations perfumed spontaneous beating conditions were then perfused with Krebs-Henseleit solution (KH solution, $\mathrm{pH} 7.4$, at $37^{\circ} \mathrm{C}$ ) containing in mM: $\mathrm{NaCl} 115, \mathrm{NaHCO}_{3} 25$, $\mathrm{KCl} 4.7, \mathrm{CaCl}_{2} 2.0, \mathrm{MgCl}_{2} 1.2, \mathrm{KH}_{2} \mathrm{PO}_{4} 1.2$, and glucose 10 . The $\mathrm{KH}$ solution was presaturated with a gas mixture containing $95 \% \mathrm{O}_{2}$ and $5 \% \mathrm{CO}_{2}$, and the heart was perfused at a constant pressure of $75 \mathrm{~cm} \mathrm{H}_{2} \mathrm{O}$ for NMR spectrometry or at a flow rate of $7 \mathrm{ml} / \mathrm{min}$ using a peristaltic pump for fluorometry. The perfused hearts were exposed to $40 \mathrm{~min}$ of global ischemia by clamping the perfusion flow line, and were then reperfused for $40 \mathrm{~min}$. In the treatment groups, each concentration of dipeptide was introduced into the perfusate $4 \mathrm{~min}$ before the start of ischemia, and each drug was also added to the perfusate during reperfusion. Hearts used for examination of apoptotic cells and caspase- 3 activity were subjected to $1 \mathrm{~h}$ of ischemia and $5 \mathrm{~h}$ of reperfusion. cLY or LY was administered for $4 \mathrm{~min}$ before ischemia and for $5 \mathrm{~h}$ throughout reperfusion.

Measurement of Myocardial Function Coronary flow (FR) during NMR analysis was measured continuously with an in-line flow probe connected to an ultrasonic flow meter (transonic T101, Advance, Ithaca, NY, U.S.A.). A latex balloon (Hirokawa, Niigata, Japan) was introduced into the left ventricle via the left atrium and connected to a strain-gauge transducer (MIP-5100, Baxer, Tokyo, Japan) for the measurement of the isovolumic left ventricular pressure. The left ventricular end-diastolic pressure (LVEDP) was adjusted to $10 \mathrm{mmHg}$ during the equilibration period in each heart, and the volume of the balloon was unchanged during the experiments. The left ventricular developed pressure (LVDP) was calculated by subtracting the LVEDP from the left ventricular systolic pressure.

${ }^{31}$ P-NMR Measurement and Data Analysis ${ }^{31} \mathrm{P}-\mathrm{NMR}$ spectra were monitored along with simultaneous recordings of ventricular pressure in the ischemia-reperfusion experiments. ${ }^{31} \mathrm{P}-\mathrm{NMR}$ spectra were obtained at $161.8 \mathrm{MHz}$ on a GSX 400 spectrometer (JEOL, Tokyo, Japan) equipped with a 9.4-Tesla vertical-bore magnet. For each spectrum, 90 freeinduction decays (4 min) were accumulated after 45-degree flip-angle pulses $(18 \mu \mathrm{s})$ using $4 \mathrm{k}$ data points and a $15.015 \mathrm{kHz}$ spectral width with a repetition time of $2 \mathrm{~s}$. Accumulated free-induction decays (FID) were filtered exponentially, resulting in a broadening of $30 \mathrm{~Hz}$.

Phosphocreatine $(\mathrm{PCr})$, inorganic phosphate $(\mathrm{Pi})$ and $\beta$ ATP were quantified by comparison with a capillary tube of standard methylenediphosphonic acid $(0.25 \mathrm{M})$ fixed inside the NMR tube. Phosphate peaks expressed as percentages of control values were determined by measuring the area under each resonance peak. The subsequent relative intensities of each peak were used for quantitative analysis. Datum Station ALICE software (JEOL DATUM, Tokyo, Japan) was used to determine the area under each peak. The intracellular $\mathrm{pH}$ $\left(\mathrm{pH}_{\mathrm{i}}\right)$ was calculated from the chemical shift between the $\mathrm{PCr}$ and Pi resonances. 
Mitochondrial Fluorometric Measurements after Changes in the $\mathrm{Ca}^{2+}$ Concentration or $\mathrm{pH}$ in the Perfusate Mitochondria were isolated from guinea-pig hearts as previously described. ${ }^{13,14)}$ The suspensions were incubated at $24^{\circ} \mathrm{C}$ in a normal medium containing respiratory substrates (composition in mm: sucrose 250, $\mathrm{MgCl}_{2} 1, \mathrm{KH}_{2} \mathrm{PO}_{4}$ 1 , succinate 10 , malate 5 and 3-morpholinopropanesulfonic acid (MOPS) 20 adjusted to $\mathrm{pH} 7.4$ with $\mathrm{KOH}$ ) and intracellular ionic compositions $\left(100 \mathrm{nM} \mathrm{Ca}^{2+}, 10 \mathrm{mM} \mathrm{Na}^{+}\right.$, and $110 \mathrm{mM} \mathrm{K}^{+}$) containing the $\mathrm{Ca}^{2+}$ fluoroprobe fura-2AM $(10 \mu \mathrm{M})$ and $0.025 \%$ cremophor EL. A $0.5-\mathrm{ml}$ aliquot of mitochondria was allowed to settle on a glass coverslip on the stage of an inverted microscope (CAM230, Japan Spectroscopic Co., Tokyo, Japan) for $30 \mathrm{~min}$. The coverslip was treated with poly-L-lysine to promote mitochondrial adhesion. Fura- $2 \mathrm{Ca}^{2+}$ signals were measured at $500 \mathrm{~nm}$ as the ratio of emitted fluorescence (R340/380) after excitation at $340 \mathrm{~nm}$ (F340) and $380 \mathrm{~nm}$ (F380). After the loading of fura2 for a period of $30 \mathrm{~min}$, the amplitude of F340 from treated mitochondria increased by 5-7-fold compared with that of unloaded mitochondria. The mitochondrial $\mathrm{Ca}^{2+}$ signal after preloading with high $\mathrm{Ca}^{2+}$ concentrations $(10 \mu \mathrm{M})$ for over 5 min was markedly increased by lowering the $\mathrm{Ca}^{2+}$ concentration from a high to a physiologically low level $(100 \mathrm{~nm})$ or by acidifying the perfusate ( $\mathrm{pH} 7.5$ to 6.5 ). We then determined whether each dipeptide $\left(10^{-6} \mathrm{M}\right)$ suppressed the $\mathrm{Ca}^{2+}$ increase induced by these manipulations. MPTP related compounds also were tested in the same manner. The final mitochondrial protein concentration was adjusted to 30 $35 \mathrm{mg} / \mathrm{ml}$ by dilution.

Electron Paramagnetic Resonance (EPR) Spectrometry-Measurement of the Quenching Effect of Superoxide Anion Radicals and Hydroxyl Radicals The effect of each peptide on production of the superoxide anion radical $\left(\mathrm{O}_{2}^{-}\right)$and hydroxyl radical $\left({ }^{\circ} \mathrm{OH}\right)$ was determined using EPR spectrometry as reported previously ${ }^{13)}$ with some modifications. The final concentration of each peptide for testing of radical quenching was $2.5 \times 10^{-6}-2.5 \times 10^{-3} \mathrm{M}$. The conditions of EPR spectrometry (JES-RE, JEOL Co., Ltd., Tokyo, Japan) used to estimate the concentration of $\mathrm{O}_{2}^{-}$radicals and ' $\mathrm{OH}$ were as follows: magnetic field: $335.7 \pm 5 \mathrm{mT}$; power: $4 \mathrm{~mW} 9.414 \mathrm{GHz}$; modulation: $100 \mathrm{KHz} \cdot 1 \times 0.079 \mathrm{mT}$; response: $0.1 \mathrm{~s}$; temperature: $25^{\circ} \mathrm{C}$; amplitude: 160 ; sweep time: $2 \mathrm{~min}$.

For the analysis of $\mathrm{O}_{2}^{-}$radicals, hypoxanthine, DETAPAC, each peptide or vehicle (DMSO), DMPO, and XOD were added to a test tube and mixed for $10 \mathrm{~s}$. The mixture was transferred to a special flat cell for the analysis of the DMPO spin adducts of $\mathrm{O}_{2}^{-}$radicals. The assay was performed $45 \mathrm{~s}$ after the addition of XOD. The signal intensities were evaluated from the peak height of the first signal of the DMPO- $\mathrm{O}_{2}^{-}$ spin adduct relative to the intensity of the $\mathrm{Mn}^{2+}$ signal, with an internal standard used to correct measurement error.

For the analysis of ${ }^{\cdot} \mathrm{OH}, \mathrm{FeSO}_{4}$ solution, hydrogen peroxide $\left(\mathrm{H}_{2} \mathrm{O}_{2}\right)$, each peptide or vehicle $(0.5 \%$ methyl cellulose $)$, and DMPO were mixed in a test tube. The amount of DMPO-OH spin adducts that formed was estimated exactly $45 \mathrm{~s}$ after DMPO was added. The signal intensities were evaluated from the peak height of the second signal of the quartet of the DMPO- ${ }^{-} \mathrm{OH}$ spin adduct relative to the intensity of the $\mathrm{Mn}^{2+}$ signal.
Examination Procedures for the Detection of Apoptosis-Histological Examination and Assessment of Internucleosomal DNA-cleavage by the Terminal Deoxy-Nucleotidyl Transferase-Mediated Deoxyuridine Triphosphate (dUTP) Nick-End Labeling (TUNEL) Method and Measurement of Caspase-3 Activity The Langendorff heart preparations were perfused with normal Krebs-Henseleit solution as previously described for ${ }^{31} \mathrm{P}-\mathrm{NMR}$ measurement. Subsequent to an equilibration period of $30 \mathrm{~min}$ required to stabilize mechanical function, the perfusate was rerplated with a modified $\mathrm{KH}$ solution in which $10 \mathrm{~mm}$ glucose was replaced with by $5 \mathrm{~mm} 2$-deoxy-D-glucose and $5 \mathrm{~mm}$ glucose $4 \mathrm{~min}$ before $1 \mathrm{~h}$ ischemia. ${ }^{15)}$ After reperfusion for $5 \mathrm{~h}$ the left ventricle was cut into several pieces. Each peptide $\left(10^{-6} \mathrm{M}\right)$ was introduced into the modified perfusate for $4 \mathrm{~min}$ before the start of ischemia, and then reperfused with the drug-containing medium of the perfusate. The changes in cellular levels of high phosphorous energy in the heart were monitored with ${ }^{31} \mathrm{P}-\mathrm{NMR}$ together with simultaneous recordings of LVDP, LVEDP and FR. The proximal portions of the isolated Langendorff hearts were fixed for $2 \mathrm{~h}$ at room temperature with phosphate-buffered solution containing $2 \%$ paraformaldehyde and embedded in paraffin for subsequent routine histological examination and the TUNEL staining. ${ }^{15,16)}$

Other sections of each heart were stored in liquid nitrogen for the measurement of the activity of caspase- 3 using a CPP32/caspase-3 fluorometric protease assay kit. ${ }^{17)}$ The assay is based on the detection of the cleavage of substrate DEVD-AFC (AFC: 7-amino-4-trifluoromethyl coumarin). DEVD-AFC emits blue light $\left(\lambda_{\max }=400 \mathrm{~nm}\right)$; upon cleavage of the substrate by CPP32 or related caspases, free AFC emits yellow-green fluorescence $\left(\lambda_{\max }=505 \mathrm{~nm}\right)$, which can be quantified using a fluorometer. Comparison of the fluorescence of AFC from an apoptotic sample with an uninduced control allows the determination of the fold-increase in CPP32 activity. The uninduced control was a heart preparation, which was perfused at $30 \mathrm{~min}$ with normal solution (control-1).

Statistical Analysis All values are presented as means S.E.M. unless otherwise specified. The unpaired $t$ test or analysis of variance (ANOVA) test followed by Dunnett's method was used for the comparison of means between groups. Statistical significance was defined as $p<0.05$.

\section{RESULTS}

Beneficial Effects of Cyclic Dipeptide (cLY) and Newly Synthesized Non-cyclic Dipeptides (LY and YL) during Ischemia-Reperfusion in Langendorff Heart Preparations-Post-Ischemic Recovery of Contraction (LVDP), End-Diastolic Pressure (LVEDP), and Coronary Flow Rate (FR), and Heart Rate (HR) Figure 2A shows sequential changes in the contractility of the drug-free group (control) and pretreated group during ischemia-reperfusion. Actual values of LVDP (mmHg), LVEDP (mmHg) and FR ( $\mathrm{ml} / \mathrm{min}$ ), and HR (times/min) are shown in Table 1.

In the control hearts, LVDP recovered to less than $22.9 \%$ of the preischemic level (as 100\%) at $40 \mathrm{~min}$ of reperfusion. In the cLY $\left(10^{-6} \mathrm{M}\right)$-pretreated hearts during ischemia-reperfusion, there was a more marked recovery of LVDP to $95.8 \%$ 

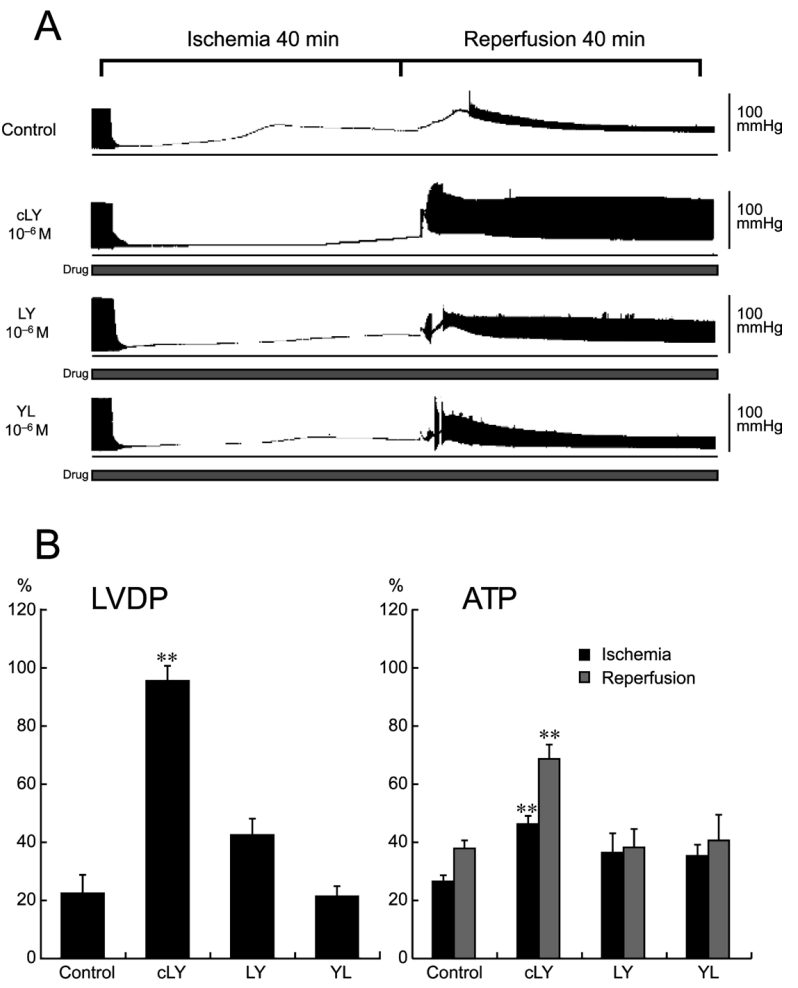

Fig. 2. (A) Beneficial Effects of cLY $\left(10^{-6} \mathrm{M}\right)$ During Ischemia-Reperfusion in Langendorff Heart Preparations

Treatment with cLY enhanced the recovery of LVDP after reperfusion compared to the controls, LY and YL.

(B) Post-Ischemic Recovery of LVDP by Reperfusion in Untreated Heart (Control), and Hearts Treated with cLY, LY or YL (Left) and the Changes in High Phosphorous Energy (ATP) during $40 \mathrm{~min}$ of Ischemia and a Subsequent 40 min of Reperfusion (Right)

The level of ATP at the end of ischemia and reperfusion was significantly higher for cLY-treated hearts than in the control. $* * p<0.01$; significantly different from the control value. Data are expressed as the mean values of 6 preparations. Vertical lines represent S.E.M. of the preischemic value $(p<0.01$ compared to control). The recovery of LVDP to preischemic values in cLY-pretreated hearts (Fig. 2B) was greater than that in LY- and YL-treated hearts $(42.8,21.6 \%$, respectively).

LVEDP at the end of 40-min ischemia (ischemic contracture) was significantly lower in hearts pretreated with cLY $\left(10^{-6} \mathrm{M}\right)$ during ischemia and reperfusion than in untreated, LY-, or YL-treated hearts, as shown in Table 1. The main feature in the recovery of the postischemic function was the difference in end-diastolic pressure between the control and drug-treated hearts.

At the end of reperfusion in the control hearts, FR was significantly lower than the preischemic level. However, compared to the control, hearts pretreated with cLY showed significant differences at the end of reperfusion. There was no significant difference between the control, LY, and YL. The rate of HR recovery in pre- and posttreated groups of Langendorff heart preparations exposed to $\operatorname{cLY}\left(10^{-6} \mathrm{M}\right)$ was 94 and $70 \%$ at the end of reperfusion, respectively $(p<0.05$ compared to control).

In posttreated group of Langendorff heart preparations exposed to cLY $\left(10^{-6} \mathrm{M}\right)$ during reperfusion, the rate of recovery of LVDP was $75 \%(p<0.05$ compared to control). The administration of cLY during reperfusion increased LVDP gradually, as shown at $\mathrm{Na}^{+}-\mathrm{H}^{+}$exchange inhibitors in our previous paper. ${ }^{18)}$

Effect of cLY on High Phosphorous Energy during Ischemia and Reperfusion Determined by ${ }^{31}$ P-NMR Spectroscopy High phosphorous energy, as represented by $\beta$ ATP levels, is presented graphically as percentages relative to the preischemic baseline with the post-ischemic LVDP in Fig. 2B. At the end of 40-min ischemia, significant differences in the preservation of ATP were obtained in hearts pretreated with cLY when compared to the control, LY, and YL groups. During reperfusion, there was a resynthesis of ATP in the pretreated hearts. The level of ATP at the end of 40min reperfusion in the cLY groups was significantly higher

Table 1. Left Ventricular Developed Pressure (LVDP), Ventricular End Diastolic Pressure (LVEDP), Coronary Flow Rate (FR), and Heart Rate (HR) Changes during Ischemia-Reperfusion of Langendorff Hearts

\begin{tabular}{|c|c|c|c|c|c|c|c|c|}
\hline & & \multirow{2}{*}{$n$} & \multicolumn{3}{|c|}{ LVDP (mmHg) } & \multicolumn{3}{|c|}{ LVEDP (mmHg) } \\
\hline & & & Pre & Isch & Rep & Pre & Isch & Rep \\
\hline Control & & 6 & $63.3 \pm 7.8$ & 0 & $24.7 \pm 5.3$ & 10 & $39.3 \pm 4.1$ & $41.5 \pm 1.9$ \\
\hline Pre-cLY & $10^{-6} \mathrm{M}$ & 6 & $65.2 \pm 4.2$ & 0 & $62.5 \pm 7.4^{*}$ & 10 & $14.8 \pm 1.8^{* *}$ & $13.7 \pm 4.3^{* *}$ \\
\hline LY & $10^{-6} \mathrm{M}$ & 6 & $62.8 \pm 4.5$ & 0 & $26.2 \pm 4.9$ & 10 & $36.2 \pm 1.8$ & $36.2 \pm 1.8$ \\
\hline YL & $10^{-6} \mathrm{M}$ & 6 & $61.5 \pm 13.8$ & 0 & $13.3 \pm 4.3$ & 10 & $36.4 \pm 4.9$ & $36.4 \pm 4.9$ \\
\hline \multirow[t]{3}{*}{ Post-cLY } & $10^{-6} \mathrm{M}$ & 5 & $58.1 \pm 4.7$ & 0 & $43.6 \pm 4.2^{* *}$ & 10 & $37.0 \pm 5.7$ & $26.7 \pm 4.8 * *$ \\
\hline & & & \multicolumn{3}{|c|}{$\mathrm{FR}(\mathrm{ml} / \mathrm{min})$} & \multicolumn{3}{|c|}{ HR (times/min) } \\
\hline & & & Pre & Isch & Rep & Pre & Isch & Rep \\
\hline Control & & 6 & $10.4 \pm 0.5$ & 0 & $4.8 \pm 0.7$ & $180 \pm 10.2$ & 0 & $65.2 \pm 7.2$ \\
\hline Pre-cLY & $10^{-6} \mathrm{M}$ & 6 & $10.5 \pm 1.0$ & 0 & $8.4 \pm 0.7 * *$ & $191 \pm 11.0$ & 0 & $180 \pm 10.0^{*}$ \\
\hline LY & $10^{-6} \mathrm{M}$ & 6 & $9.4 \pm 0.9$ & 0 & $5.4 \pm 0.9$ & $183 \pm 9.5$ & 0 & $73.2 \pm 8.7$ \\
\hline YL & $10^{-6} \mathrm{M}$ & 6 & $9.8 \pm 0.5$ & 0 & $4.8 \pm 0.9$ & $189 \pm 12.0$ & 0 & $59.0 \pm 11.0$ \\
\hline Post-cLY & $10^{-6} \mathrm{M}$ & 5 & $10.4 \pm 1.2$ & 0 & $5.8 \pm 0.7 *$ & $186 \pm 9.7$ & 0 & $130 \pm 6.7 * *$ \\
\hline
\end{tabular}

Changes during $40 \mathrm{~min}$ of ischemia and a subsequent $40 \mathrm{~min}$ of reperfusion. Values are the mean \pm S.E.M. $* p<0.01, * * p<0.05$ : significantly different from control values. Pre, preischemia; Isch, ischemia; Rep, reperfusion. Drug was introduced into the perfusion on-line 4 min before the start of ischemia (Pre-). Drug was introduced into the perfusate for reperfusion (Post-) 
A
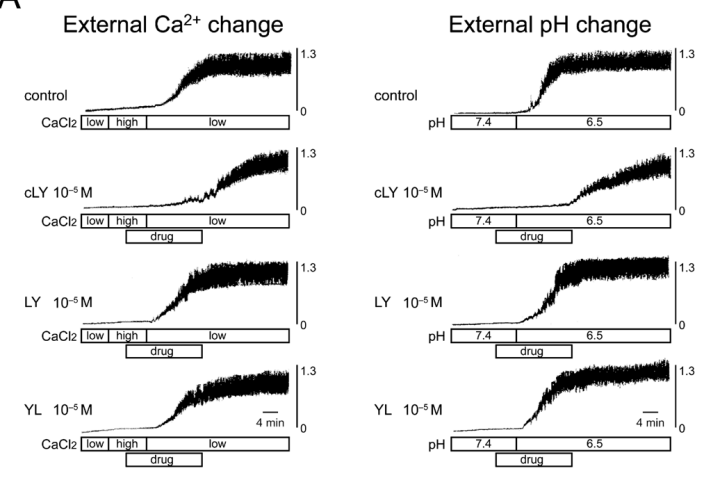

B

External $\mathrm{Ca}^{2+}$ change
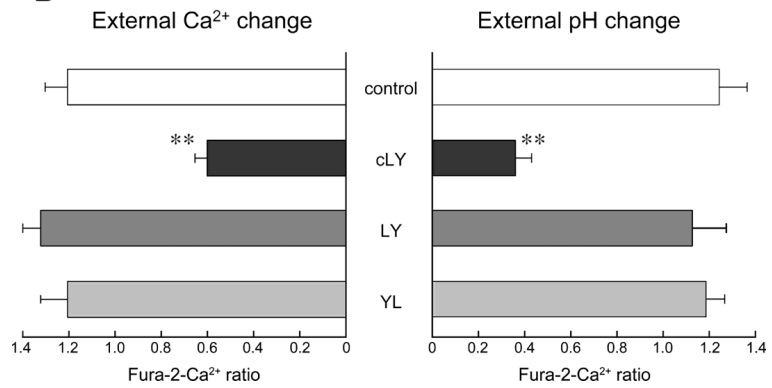

Fig. 3. (A) Recordings of Mitochondrial $\mathrm{Ca}^{2+}$ from Fura-2-Loaded Mitochondria Preparations Affected by Changing the $\mathrm{Ca}^{2+}$ Concentrations or $\mathrm{pH}$ in the Perfusate

The mitochondrial $\mathrm{Ca}^{2+}$ signal $\left(\left[\mathrm{Ca}^{2+}\right]_{\mathrm{m}}\right)$ gradually increased with extremely high $\mathrm{Ca}^{2+}(10 \mu \mathrm{M})$, and perfusion with a low $\mathrm{Ca}^{2+}$-content solution $(100 \mathrm{nM})$ also rapidly increased the mitochondrial $\mathrm{Ca}^{2+}$ level (left, top). Perfusate acidification ( $\mathrm{pH}$ 6.5) in the low $\mathrm{Ca}^{2+}$-content solution $(100 \mathrm{~nm})$ produced a more rapid $\mathrm{Ca}^{2+}$ signal elevation than that observed on changing $\mathrm{Ca}^{2+}$ content (right, top). $\operatorname{cLY}\left(10^{-5} \mathrm{M}\right)$ but not LY and YL a $10^{-5} \mathrm{M}$ reduced the increase in mitochondrial $\mathrm{Ca}^{2+}$ induced signals by the displacement of perfusate.

(B) Comparison of the Inhibition of $\mathrm{Ca}^{2+}-$ Uptake into Mitochondria in the Presence of cLY, LY, or YL

The mitochondrial $\mathrm{Ca}^{2+}$ level was elevated by an external $\mathrm{Ca}^{2+}$ concentration change (left) or external acidification (right). The $\left[\mathrm{Ca}^{2+}\right]_{\mathrm{m}}$ elevation was reduced by cLY. $* * p<0.01$, significantly different from the control (drug-free) values. Values are expressed as the mean values of $3-5$ preparations. Vertical lines represent the S.E.M.

than in the control, LY, and YL groups. A rapid decrease in $\mathrm{PCr}$ was observed during ischemia in all groups. However, $\mathrm{pH}_{\mathrm{i}}$ values in these hearts at $40 \mathrm{~min}$ of reperfusion were not significantly different from the control value.

Mitochondrial $\mathrm{Ca}^{2+}\left(\left[\mathrm{Ca}^{2+}\right]_{\mathrm{m}}\right)$ Measurements with Fura-2 AM The mitochondrial fura- $2 \mathrm{Ca}^{2+}$ signal $\left(\left[\mathrm{Ca}^{2+}\right]_{\mathrm{m}}\right)$ increased steadily and linearly but remained at only $10 \%$ excess at extremely high $\mathrm{Ca}^{2+}$ concentrations $(1 \mu \mathrm{M}-1 \mathrm{~mm})$ of the perfusate (Fig. 3A). The displacement of the normal matrix $\mathrm{Ca}^{2+}$ concentration $(100 \mathrm{~nm})$ with perfusate led to a rapid and marked increase of up to about 9.2fold. Pretreatment of mitochondria with cLY $\left(10^{-6}\right.$ and $10^{-5} \mathrm{M}$ ) markedly suppressed the increase in $\left[\mathrm{Ca}^{2+}\right]_{\mathrm{m}}$, that occurred in the drug-free perfusate by 72.0 and $50.0 \%$, respectively. However, the non-cyclic dipeptides LY and YL $\left(10^{-5} \mathrm{M}\right)$ did not suppress the increase in $\left[\mathrm{Ca}^{2+}\right]_{\mathrm{m}}$ (Fig. 3B).

Changing the $\mathrm{pH}$ from 7.4 to 6.5 in a low- $\mathrm{Ca}^{2+}$ perfusate $(100 \mathrm{~nm})$ maximally elevated the $\left[\mathrm{Ca}^{2+}\right]_{\mathrm{m}}$ up to about ten-fold relative to the $\mathrm{pH} 7.4$ perfusate (Fig. $3 \mathrm{~A}$ ). The appreciable $\left[\mathrm{Ca}^{2+}\right]_{\mathrm{m}}$ elevation induced by acidification $(0.13$ to 1.25$)$ was reduced by pretreatment with $\mathrm{CLY}$ at $10^{-6} \mathrm{M}$ and $10^{-5} \mathrm{M}$ by 75 and $28.8 \%$, respectively. LY and YL $\left(10^{-5} \mathrm{M}\right)$ did not suppress the increase in $\left[\mathrm{Ca}^{2+}\right]_{\mathrm{m}}$ (Fig. 3B). The acid-induced

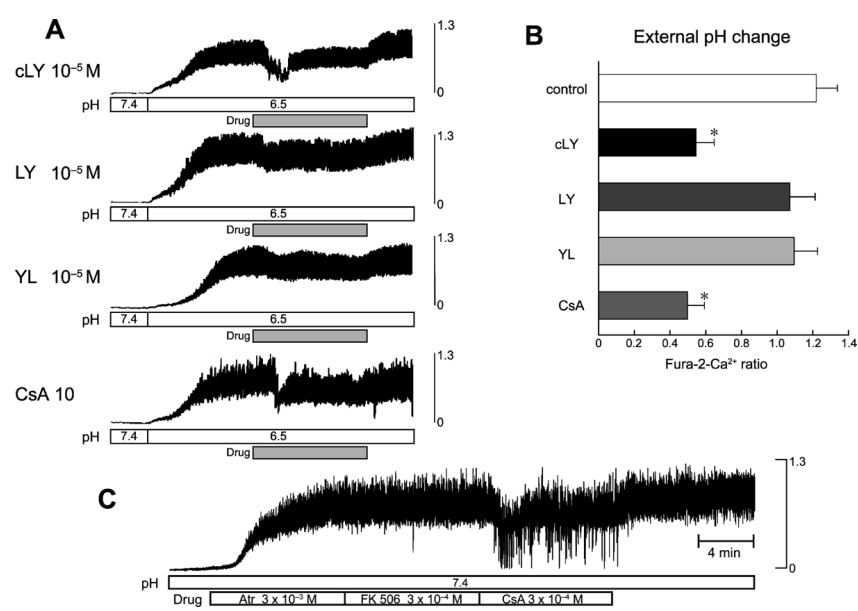

Fig. 4. (A) The $\left[\mathrm{Ca}^{2+}\right]_{\mathrm{m}}$ Elevation That Was Brought about by Perfusate Acidification Was Reduced by the Infusion of $\operatorname{cLY}\left(10^{-5} \mathrm{M}\right)$. (B) The Decrease in $\left[\mathrm{Ca}^{2+}\right]_{\mathrm{m}}$ Caused by the Administration of cLY Was Greater Than That Induced LY or YL. (C) The $\left[\mathrm{Ca}^{2+}\right]_{\mathrm{m}}$ Elevation Brought about by Perfusate Acidification Decreased after Addition of the MPTP Inhibitor Cyclosporin A $(\mathrm{CsA})\left(3 \times 10^{-4} \mathrm{M}\right)$, but Was Unaffected by FK $506\left(3 \times 10^{-4} \mathrm{M}\right)$ Which Does Not Inhibit MPTP Opening

Treatment with the mitochondrial PTP opener atractiroside (Atr) $\left(3 \times 10^{-3} \mathrm{M}\right)$ resulted essentially in the same $\left[\mathrm{Ca}^{2+}\right]_{\mathrm{m}}$ elevation brought about by perfusate acidification and an external $\mathrm{Ca}^{2+}$ concentration change.

increase in $\left[\mathrm{Ca}^{2+}\right]_{\mathrm{m}}$ was greater and more rapid than that caused by perfusion with the low-Ca ${ }^{2+}$ perfusate.

As shown in Fig. 4A, the addition of cLY $\left(10^{-5} \mathrm{M}\right)$ to the perfusate released $\mathrm{Ca}^{2+}$ from the mitochondria. The effect of cLY and CsA $\left(10^{-4} \mathrm{M}\right)$, which inhibits MPTP opening, was greater than that of LY and YL (Fig. 4B). In contrast, Atr $\left(10^{-3} \mathrm{M}\right)$, which opens the MPTP, caused increases in $\left[\mathrm{Ca}^{2+}\right]_{\mathrm{m}}$ similar to those observed on acidifying the perfusate or changing its $\mathrm{Ca}^{2+}$ concentration. Treatment with $\mathrm{cLY}$ and CsA released mitochondrial $\mathrm{Ca}^{2+}$ that had been increased by changes in the perfusates $\mathrm{Ca}^{2+}$ content, acidification, or treatment with Atr (Fig. 4C) but not FK506, which inhibits the phosphatase calcineurin without inhibiting MPTP opening. The pretreatment with $10^{-4} \mathrm{M}$ CsA attenuated mitochondrial $\mathrm{Ca}^{2+}$ release. The addition of Ru360, ryanosine, verapamil, diazoxide, and chlonazepam to perfusate increased steadily and constantly the change in concentration of $\mathrm{Ca}^{2+}$ released from mitochondria (Fig. 5). These effects were similar to those seen with cLY or CsA which inhibits MPTP.

In Vitro Free Radical Quenching Activity of cLY, LY, and YL In the experiment on quenching activity, cLY, LY, and $\mathrm{YL}$ at final concentrations from $2.5 \times 10^{-6}$ to $2.5 \times 10^{-3} \mathrm{M}$ dose-dependently quenched the generation of ${ }^{\circ} \mathrm{OH}$. The $\mathrm{IC}_{50}$ (concentration causing a 50\% scavenging effect) of cLY, LY and YL was $1.8 \times 10^{-4} \mathrm{M}, 2.0 \times 10^{-3}$, and $1.3 \times 10^{-3}$, respectively. cLY also showed quenching activity against $\mathrm{O}_{2}^{-}$radicals at $2.5 \times 10^{-3} \mathrm{M}$ with a $30 \%$ decrease, but LY and YL produced almost no change. However, the $\mathrm{IC}_{50}$ value of cLY could not be measured because it did not cause $50 \%$ inhibition. The $\mathrm{IC}_{50}$ of vitamin $\mathrm{C}$ was $2.4 \times 10^{-3} \mathrm{M}\left({ }^{\circ} \mathrm{OH}\right)$ and $6.3 \times 10^{-5} \mathrm{M}\left(\mathrm{O}_{2}^{-}\right.$radicals $)$; the radical quenching activity of cLY against ${ }^{\circ} \mathrm{OH}$ was stronger than that of vitamin $\mathrm{C}$.

Detection of Apoptosis Examples of apoptotic tissues obtained after the various treatments are shown in our previous report. ${ }^{18)}$ Apoptotic cells were first observed in the ven- 
Table 2. Left Ventricular Developed Pressure (LVDP), Ventricular End Diastolic Pressure (LVEDP), and Coronary Flow Rate (FR) and High Phosphorous Energy (PCr, $\beta$-ATP) Changes during Ischemia-Reperfusion of Langendorff Hearts for the TUNEL and Caspase-3-Activity Measurements

\begin{tabular}{|c|c|c|c|c|c|c|c|c|c|c|}
\hline & \multirow{2}{*}{$n$} & \multicolumn{3}{|c|}{ LVDP (mmHg) } & \multicolumn{3}{|c|}{ LVEDP (mmHg) } & \multicolumn{3}{|c|}{$\mathrm{FR}(\mathrm{ml} / \mathrm{min})$} \\
\hline & & Pre & Isch & Rep & Pre & Isch & Rep & Pre & Isch & Rep \\
\hline \multirow{5}{*}{$\begin{array}{l}\text { Control } \\
\text { cLY } 10^{-6} \mathrm{M} \\
\text { LY } \quad 10^{-6} \mathrm{M}\end{array}$} & 5 & $62.3 \pm 8.6$ & 0 & $2.0 \pm 1.2$ & 10 & $34.2 \pm 4.1$ & $41.6 \pm 2.0$ & $10.4 \pm 1.0$ & 0 & $0.5 \pm 0.1$ \\
\hline & 5 & $60.5 \pm 8.5$ & 0 & $6.8 \pm 1.7$ & 10 & $24.7 \pm 2.3 *$ & $35.7 \pm 2.8^{*}$ & $10.8 \pm 2.3$ & 0 & $2.8 \pm 1.0$ \\
\hline & 5 & $61.7 \pm 7.9$ & 0 & $3.4 \pm 1.5$ & 10 & $31.8 \pm 3.5$ & $40.7 \pm 4.0$ & $10.5 \pm 1.7$ & 0 & $0.7 \pm 0.8$ \\
\hline & \multirow{2}{*}{$n$} & \multicolumn{3}{|c|}{ ATP (\%) } & \multicolumn{3}{|c|}{$\mathrm{PCr}(\%)$} & & & \\
\hline & & Pre & Isch & Rep & Pre & Isch & Rep & & & \\
\hline Control & 5 & 100 & $12.6 \pm 2.0$ & $12.4 \pm 2.2$ & 100 & 0 & $4.8 \pm 2.3$ & & & \\
\hline $\mathrm{cLY} 10^{-6} \mathrm{M}$ & 5 & 100 & $18.9 \pm 3.2$ & $20.7 \pm 2.7$ & 100 & 0 & $38.7 \pm 12.7 *$ & & & \\
\hline LY $10^{-6} \mathrm{M}$ & 5 & 100 & $15.7 \pm 3.5$ & $15.7 \pm 3.0$ & 100 & 0 & $10.8 \pm 8.7$ & & & \\
\hline
\end{tabular}

Changes during $1 \mathrm{~h}$ of ischemia and a subsequent $5 \mathrm{~h}$ of reperfusion. Values are the mean \pm S.E.M. $* p<0.05$ : significantly different from control values. Pre, preischemia; Isch, ischemia; Rep, reperfusion.

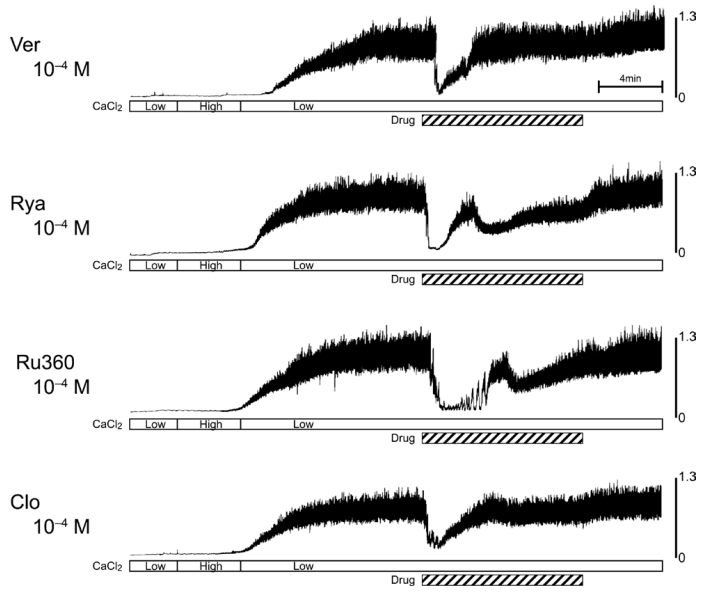

Fig. 5. Mitochondrial $\mathrm{Ca}^{2+}$ Uptake by $\mathrm{Ca}^{2+}$-Content Changes of the Perfusate Decreased by Treatment with Verapamil (Ver), Ryanosine (Rya), Ru360, and Chlonazepam (Clo) at $10^{-4} \mathrm{M}$ as Similar with Cyclosporin A Which Inhibits MPTP as Shown in Fig. 4

tricle after $5 \mathrm{~h}$ of reperfusion following $1 \mathrm{~h}$ of ischemia with $\mathrm{KH}$ solution containing 2-deoxy-D-glucose. ${ }^{15)}$ As shown in Fig. $6 \mathrm{~A}, 5 \mathrm{~h}$ of reperfusion resulted in an average of $27.7 \pm 2.4$ apoptotic cells per 100 microscopic fields, but $4 \mathrm{~h}$ of reperfusion did not produce apoptotic cells. cLY and LY treatment $\left(10^{-6} \mathrm{M}\right)$ reduced the incidence of apoptosis in the ischemic and reperfused myocardium to an average of $4.5 \pm 1.1(p<0.05)$ and 23.6 2 2.6 (not significant) cells per 100 microscopic fields, respectively, compared with the control. The effect of cLY on apoptotis was greater than that of LY $(p<0.05)$.

Caspase- 3 activity in the control and apoptotic samples was measured in the same frozen tissues using the TUNEL method. Control-1 was heart preparations perfused for 30 min with normal $\mathrm{KH}$ solution, while control-2 was hearts subjected to $1 \mathrm{~h}$ of ischemia and $5 \mathrm{~h}$ of reperfusion with a drug-free solution (control). The decrease of caspase-3 activity in hearts pretreated with cLY (Control-1: 1.0, Control-2: 6.5 \pm 1.0 , LY: $5.9 \pm 0.9$, cLY: $2.0 \pm 0.6, p<0.05$ for control-2, $p<0.05$ for LY-treated heart) was similar to the results of TUNEL staining (Fig. 6B).
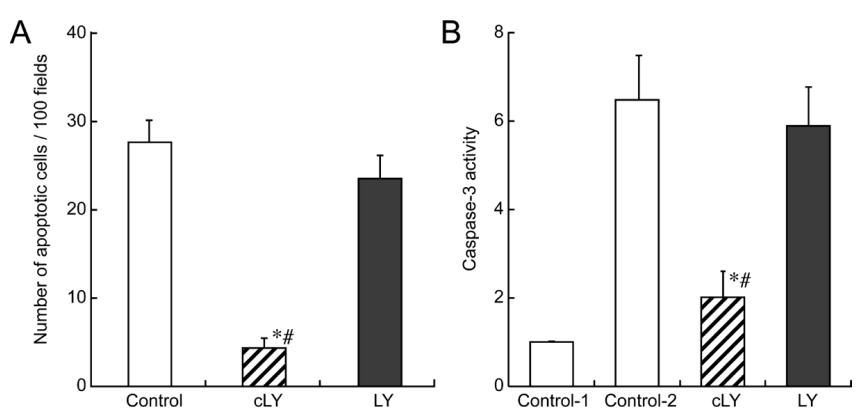

Fig. 6. (A) The Incidence of Apoptosis Observed Using the TUNEL Staining

Values are expressed as the mean of 5 preparations \pm S.E.M. and indicate the number of positively stained cells identified per 100 microscopic fields. $* p<0.05$ significantly different compared with control (drug-free) values. $\# p<0.05$ significantly different between LY and cLY-treated groups.

(B) Control-1: The Uninduced Control Was a Heart Preparation Perfused at 30 min with Normal KH Solution

Values are expressed as the mean of 5 preparations \pm S.E.M. and indicate caspase- 3 activity. $* p<0.05$ significantly different compared with the control (drug-free) values. ${ }_{\#} p<0.05$ significantly different between the cLY and LY-treated groups.

As shown in Table 2, which lists the changes in mechanical function and high phosphorous energy, the LVEDP and PCr were significantly different in hearts treated with cLY at $10^{-6} \mathrm{M}$ after $5 \mathrm{~h}$ reperfusion compared with the control $(p<0.05)$, but LY at $10^{-6} \mathrm{M}$ generated no appreciable difference. The changes in the coronary flow, LVDP, and ATP signals were also not significantly different in hearts pretreated with cLY compared to the control or LY-treated hearts. From these results, the effects of cLY on the recovery of mechanical function and tissue levels of high-energy phosphate were greater than those of LY.

\section{DISCUSSION}

In the pretreated hearts, cLY improved the outcome after ischemic injury more markedly than the newly synthesized non-cyclic dipeptides (LY and YL). cLY had most important effect on the recovery of LVDP and a significant preserving effect on tissue levels of high-energy phosphate (ATP) measured at the final stage of ischemia and after reperfusion when 
compared to the drug-free hearts. These findings strongly indicate that the mitochondrial function, in close association with the synthesis of high-energy phosphate in the form of ATP, constituted an important part of the regulatory mechanism involved in myocardial ischemic injury. Therefore, the cyclic dipeptide is likely to play an important role in its beneficial effects

On reperfusion, the cytosolic $\mathrm{Ca}^{2+}$ concentration that had increased during global ischemia rapidly returned to the control level, as previously reported. ${ }^{10,13,19)}$ The fura- $2 \mathrm{Ca}^{2+}$ signals $\left(\left[\mathrm{Ca}^{2+}\right]_{\mathrm{m}}\right)$ in isolated myocardial mitochondria preloaded with abnormally high $\mathrm{Ca}^{2+}$ levels using a superfusion technique increased rapidly, reaching a maximum during displacement with a perfusate containing cytosolic $\mathrm{Ca}^{2+}$ (ca. $100 \mathrm{~nm})$. In addition, the elevation of $\left[\mathrm{Ca}^{2+}\right]_{\mathrm{m}}$ was quickly detected on acidification of the perfusate that represented the final stage of global ischemia in the Langendorff hearts. Both elevations in the perfused mitochondrial preparation were attenuated by pretreatment with cLY. ${ }^{10,11,13)}$ From these findings, it is likely that, during reperfusion, mitochondria play an essential role in the cellular homeostasis of $\mathrm{Ca}^{2+}$ for the maintenance of cellular functions of the heart by acting as a scavenger of cytosolic $\left.\mathrm{Ca}^{2+} \cdot 5,20,21\right)$

The MPTP opener atractyloside $\left(A \operatorname{tr}, 10^{-3} \mathrm{M}\right)$ also generated increases in $\left[\mathrm{Ca}^{2+}\right]_{\mathrm{m}}$ similar to those obtained after changing the $\mathrm{Ca}^{2+}$ concentration or acidification of the perfusate. ${ }^{6,22)}$ In contrast to Atr-induced MPTP opening, pretreatment with cyclosporin A (CsA), which inhibits MPTP, depressed $\left[\mathrm{Ca}^{2+}\right]_{\mathrm{m}}$ elevation by changing the $\mathrm{Ca}^{2+}$ concentration and acidification, but not by treatment with FK506, which inhibits the phosphatase calcineurin without inhibiting MPTP opening. ${ }^{23,24)}$ Furthermore, posttreatment with CsA resulted in a release of $\mathrm{Ca}^{2+}$ from mitochondria after $\left[\mathrm{Ca}^{2+}\right]_{\mathrm{m}}$ was increased by changing the $\mathrm{Ca}^{2+}$ concentration or acidification of the perfusate. The release of accumulated $\mathrm{Ca}^{2+}$ was also affected by alkalization ( $\mathrm{pH}$ 8.5) or changing the $\mathrm{Mg}^{2+}$ concentration of the perfusate, as a well-known inhibitor of MPTP. ${ }^{25-27)}$ These effects were similar to those noted for cLY, and were greater than those observed for YL or LY. Treatment with Ru360, ryanosine, verapamil, diazoxide, and chlonazepam, which do not transport $\mathrm{Ca}^{2+}$ to mitochondria, also led to the release of $\mathrm{Ca}^{2+}$ from the mitochondria. ${ }^{18,28)}$ Detailed data will be presented in another report. Therefore, mitochondrial fura- $2 \mathrm{Ca}^{2+}$ signals resulting from changes in the $\mathrm{Ca}^{2+}$ concentration or acidification of the perfusate were clearly observed during the time course of MPTP opening or closing. The increases in $\left[\mathrm{Ca}^{2+}\right]_{\mathrm{m}}$ were suppressed by infusion of the $\mathrm{Na}^{+} / \mathrm{H}^{+}$exchange (NHE) inhibitor SM198110 ${ }^{18)}$ and many other drugs that also promote favarable LVDP recovery in the Langendorff ischemia-reperfusion injury model. ${ }^{19,27,29,30)}$ These results suggest that MPTP is closely involved in postischemic myocardial dysfunction.

Irrespective of its exact composition, the MPTP complex contains multiple targets for pharmacological investigations ${ }^{8)}$ and is involved in different pathways of apoptosis induction as a sensor for stress and damage. There is now increasing evidence that apoptosis is an important response of the myocardium to ischemia and reperfusion, which is rapid, precedes cell necrosis, and appears to contribute to the overall sequelae of cardiac injury. ${ }^{7}$ We have demonstrated that the administration of cLY reduced the number of TUNEL-posi- tive cardiomyocytes when compared with drug-free or LYtreated hearts. In the present study, cLY treatment reduced the number of TUNEL-positive cardiomyocytes and caspase3 activity after ischemia and reperfusion when compared to LY. cLY treatment also significantly improved the recovery of the left ventricular function (LVDP) and coronary flow (FR) with accompanying increases in the levels of high-energy phosphates (ATP, PCr) when compared to drug-free hearts. cLY provided greater protection than LY of the ischemic myocardium as well as hearts subjected to reperfusion procedures. The role of cLY in this response has been shown to be similar to that of the NHE inhibitor SM198110. ${ }^{18)}$ These results suggest that apoptosis may be a major manifestation of ischemia-reperfusion injury and that MPTP is closely involved in postischemic myocardial dysfunction.

Reactive oxygen species (ROS) also promote apoptosis. ${ }^{31)}$ The production of ROS within the first few minutes of reperfusion may mediate cell damage due to ischemia-reperfusion injury. ${ }^{32)}$ ROS action on mitochondria results in MPTP opening, ${ }^{33)}$ and this triggers the mitochondria-related apoptotic pathway. It is also possible that peroxidative attacks may directly damage the outer mitochondrial membrane, resulting in the nonspecific liberation of intermembrane proteins, including a fraction of cytochrome $c$, during apoptotic signaling. On in vitro EPR spectrometry, the quenching activity $\left(\mathrm{IC}_{50}\right)$ of the cyclic peptide $\mathrm{cLY}$ for the ${ }^{\circ} \mathrm{OH}$ was found to be $1.8 \times 10^{-4} \mathrm{M}$, which was greater than that of vitamin $\mathrm{C}$ $\left(2.4 \times 10^{-3} \mathrm{M}\right)$, the non-cyclic peptides LY $\left(2.0 \times 10^{-3} \mathrm{M}\right)$, or YL $\left(3 \times 10^{-3} \mathrm{M}\right)$, while quenching of the $\mathrm{O}_{2}^{-}$radical was $70 \%$ at $\mathrm{cLY} 2.5 \times 10^{-3} \mathrm{M}$ in contrast to $\mathrm{LY}$ and $\mathrm{YL}$ at $2.5 \times 10^{-3} \mathrm{M}$, which showed no quenching. The role of superoxide $\left(\mathrm{O}_{2}^{-}\right)$, $\mathrm{NO}$, and peroxynitrite $\left(\mathrm{ONOO}^{-}\right)$in myocardial ischemiareperfusion injury and preconditioning was reviewed by Fredinardy and Schulz. ${ }^{34)}$ In another of our studies on guineapig hearts, NO supplied by the NO donor FK409, ${ }^{35)}$ serotonin derivatives from safflower oil, ${ }^{19)}$ or the strongest antioxidative tea catechins (EGCg and GCg), ${ }^{26,27)}$ had cardioprotective actions, presumably by scavenging cytosolic superoxide anions. Immunoblotting analysis showed that endothelial nitric oxide synthese ((e)-NOS) was present in mitochondria and $\mathrm{ONOO}^{-}$itself also inhibited $\left[\mathrm{Ca}^{2+}\right]_{\mathrm{m}}$ influx. Based on these findings, we concluded that e-NOS exists in mitochondria and that NO may play an important protective role in perfusion cardiac injury after ischemia by inhibiting $\left[\mathrm{Ca}^{2+}\right]_{\mathrm{m}}$ influx into mitochondria, which are otherwise damaged by $\mathrm{O}_{2}^{-}$. Further research on $\mathrm{ONOO}^{-}$generation in hearts will lead to a better understanding of how to protect the heart from oxidant stress in ischemia and reperfusion injury. Additional studies of in vivo whole body EPR using nitroxyl radicals $^{36)}$ are required to more adequately resolve the relationships between oxygen radicals generated in biological systems and the rate of redox reactions of spin probes during ischemia-reperfusion.

In conclusion, in ischemia-reperfusion injury hearts, we found that the cyclic dipeptide, cLY, showed greater cardioprotective effects via the inhibition of cardiomyocyte apoptosis (caspase-3 activity) than that of the non-cyclic peptides, LY and YL, utilized as a control. These findings strongly indicate that the cyclic dipeptide skeleton, in close association with the synthesis of high-energy phosphates, plays an important role in its protection against myocardial ischemic in- 
jury. Further investigation of the cardiac effects of purified cyclic dipeptides synthesized with another peptide should provide valuable information regarding the normal physiology of cardiomyocyte apoptosis and help in the design of cardioprotective drugs.

Acknowledgments The authors wish to thank $\mathrm{Mr}$. Makoto Naruse and Mr. Minoru Fukayama (Aichi Medical University) for skillful NMR measurements and Miss Kaoru Mimura for technical assistance. This work was supported in part by a Grant-in-Aid for Scientific Research from the Ministry of Education, Culture, Sports, Science and Technology of Japan (No. 16590443), Kinjo Gakuin University-Parent Teacher Association Special Research Subsidy, and the bounty for academic research from the Research Institute of Meijo University.

\section{REFERENCES}

1) Gautschi M., Schmid J. P., Peppard T. L., Ryan T. P., Tuorto R. M., Yang X., J. Agric. Food Chem., 45, 3183-3189 (1997).

2) Takahashi K., Tadenuma M., Kitamoto K., Sato S., Agric. Biol. Chem., 38, 927-932 (1974)

3) Takaya Y., Furukawa T., Miura S., Akutagawa T., Hotta Y., Ishikawa N., Niwa M., J. Agric. Food Chem., 55, 75-79 (2007).

4) Griffiths E. J., Ocampo C. J., Savage J. S., Stern M. D., Silverman H. S., Cell Calcium, 27, 87-95 (2000).

5) Bernardi P., Rasola A., Subcell. Biochem., 45, 481-506 (2007).

6) Hausenloy D. J., Maddock H. L., Baxter G. F., Yellon D. M., Cardiovasc. Res., 55, 534-543 (2002).

7) Kroemer G., Dallaporta B., Resche-Rigon M., Ann. Rev. Physiol., 60, 619-642 (1998).

8) Smaili S. S., Hsu Y. T., Youle R. J., Russell J. T., J. Bioenerg. Biomembr., 32, 35-46 (2000).

9) Suleiman M. S., Halestrap A. P., Griffiths E. J., Pharmacol. Ther., 89, 29-46(2001).

10) Hotta Y., Fujita M., Nakagawa J., Ando H., Takeya K., Sakakibara J., J. Cardiovasc. Pharmacol., 31, 146-156 (1998).

11) Hotta Y., Nakagawa J., Ishikawa N., Wakida Y., Ando H., Takeya K., Ohashi N., Matsui K., J. Cardiovasc. Pharmacol., 37, 143-154 (2001).

12) Koike A., Abe T., Hotta Y., Takeya K., Kodama I., Toyama J., J. Thorac. Cardiovasc. Surg., 112, 765-775 (1996).

13) Hotta Y., Otsuka-Murakami H., Fujita M., Nakagawa J., Yajima M., Liu W., Ishikawa N., Kawai N., Masumizu T., Kohno M., Eur. J. Pharmacol., 380, 37-48 (1999).

14) Hotta Y., Ishikawa N., Ohashi N., Matsui K., Mol. Cell. Biochem., 219,
$83-90$ (2001)

15) Tong J., Cao Y., Hotta Y., Ishikawa N., Takeo T., Nishimaki H., Masuda K., Yang C.-L., Kasai K., Ikeda H., Itoh G., Basic Appl. Myol., 11, 145-152 (2002).

16) Itoh G., Tamura J., Suzuki M., Suzuki Y., Ikeda H., Koike M., Nomura M., Tong J., Ito K., Am. J. Pathol., 146, 1325-1331 (1995).

17) Casciola-Rosen L., Nicholson D. W., Chong T., Rowan K. R., Thornberry N. A., Miller D. K., Rosen A., J. Exp. Med., 183, 1957-1964 (1996).

18) Hotta Y., Nishimaki H., Takeo T., Itoh G., Yajima M., Otsuka-Murakami H., Ishikawa N., Kawai N., Huang L., Yamada K., Yamamoto S., Matsui K., Ohashi N., Eur. J. Pharmacol., 503, 109-122 (2004).

19) Hotta Y., Nagatsu A., Liu W., Muto T., Narumiya C., Lu X., Yajima M., Ishikawa N., Kawai N., Mizukami H., Sakakibara J., Mol. Cell Biochem., 238, 151-162 (2002).

20) Tani M., Neely J. R., Circ. Res., 65, 1045-1056 (1989).

21) Brooks W. W., Conrad C. H., Morgan J. P., Cardiovasc. Res., 29, 536542 (1995).

22) Machida K., Hayashi Y., Osada H., J. Biol. Chem., 277, 31243-31248 (2002).

23) Kaibori M., Inoue T., Tu W., Oda M., Kwon A. H., Kamiyama Y., Okumura T., Life Sci., 69, 17-26 (2001).

24) Fauvel H., Marchetti P., Obert G., Joulain O., Chopin C., Formstecher P., Neviere R., Am. J. Respir. Crit. Care Med., 165, 449—455 (2002).

25) Biban C., Tassani V., Toninello A., Siliprandi D., Siliprandi N., Biochem. Pharmacol., 50, 497-500 (1995).

26) Hotta Y., Huang L., Muto T., Yajima M., Miyazeki K., Ishikawa N., Fukuzawa Y., Wakida Y., Tushima H., Ando H., Nonogaki T., Eur. J. Pharmacol., 552, 123-130 (2006).

27) Hirai M., Hotta Y., Ishikawa N., Wakida Y., Fukuzawa Y., Isobe F., Nakano A., Chiba T., Kawamura N., Life Sci., 80, 1020-1032 (2007).

28) Korge P., Honda H. M., Weiss J. M., Proc. Natl. Acad. Sci. U.S.A., 99, 3312-3317 (2002).

29) Muto T., Hotta Y., Miyazeki K., Ando H., Ishikawa N., Hasegawa T., Sugimoto Y., Yamada J., Miki Y., Mol. Cell Biochem., 272, 119-132 (2005).

30) Huang L., Hotta Y., Miyazeki K., Ishikawa N., Miki Y., Sugimoto Y., Yamada J., Nakano A., Nishiwaki K., Shimada Y., Eur. J. Pharmacol., 534, 165-177 (2006).

31) Chandra J., Samali A., Orrenius S., Free Radic. Biol. Med., 29, 323 $333(2000)$.

32) Zweier J. L., Flaherty J. T., Weisfeldt M. L., Proc. Natl. Acad. Sci. U.S.A., 84, 1404-1407 (1987)

33) Vercesi A. E., Kowaltowski A. J., Grijalba M. T., Meinicke A. R., Castilho R. F., Biosci. Rep., 17, 43-52 (1997).

34) Ferdinandy P., Schulz R., Br. J. Pharmacol., 138, 532-543 (2003).

35) Cao Y., Hotta Y., Shioi K., Nagata Y., Kawai N., Ishikawa N., J. Cardiovasc. Pharmacol., 38, 593-605 (2001).

36) Yajima M., Muto T., Huang L., Hotta Y., Ishikawa N., J. Pharmacol. Sci., 97, 239 (2005). 